\title{
STUDI RELEVANSI MATA PELAJARAN PRODUKTIF PAKET KEAHLIAN TEKNIK GAMBAR MESIN DENGAN STANDAR KOMPETENSI KERJA NASIONAL INDONESIA DI SMK
}

\author{
Muhammad V. Ramdani ${ }^{1}$, Aam Hamdani ${ }^{2}$, Dede Suhayat ${ }^{3}$ \\ Universitas Pendidikan Indonesia \\ Jl. Dr. Setiabudhi No. 229 Bandung 40154 \\ mvramdani@gmail.com
}

\begin{abstract}
ABSTRAK
Penelitian ini bertujuan untuk menghasilkan deskripsi relevansi materi Mata Pelajaran Produktif Paket Keahlian Teknik Gambar Mesin dengan SKKNI. Metode yang digunakan dalam penelitian ini adalah deskriptif analitik dengan teknik pengumpulan data berupa teknik dokumentasi, wawancara, dan angket. Hasil penelitian menunjukan bahwa materi mata pelajaran Teknik Gambar Mesin di SMK Negeri 2 Bandung dengan SKKNI secara keseluruhan memiliki tingkat kesesuaian dengan persentase 80,09\% dengan kategori relevan. Berdasarkan hasil penelitian ini, diharapkan sekolah, dapat mensosialisasikan kerelevanan materinya, kepada guru pengampu di Sekolah khususnya Guru Pengampu Mata Pelajara Produktif Paket Keahlian Teknik Gambar Mesin. Tujuan yang ingin dicapai sekolah dapat terwujud. Guru pengampu paket keahlian dapat membantu terlaksananya pembelajaran yang optimal dengan memberikan ilustrasi pengaplikasian materi dalam mata pelajaran ke dunia industri berdasarkan pemetaan sekuen untuk merangsang minat siswa dalam mengikuti pengajaran.
\end{abstract}

Kata kunci: gambar mesin, SKKNI, kompetensi gambar, gambar teknik

\section{PENDAHULUAN}

Pendidikan memiliki peranan penting dalam mencapai tujuan pembangunan nasional. Seiring dengan laju pembangunan saat ini telah banyak pengaruh era globalisasi yang menimbulkan perubahan di segala bidang. Kondisi kebutuhan dan tantangan dunia kerja yang semakin kompleks menuntut tenaga kerja sebagai sumber daya manusia harus mampu berkompetisi dengan bekal keahlian yang profesional (Idi, 2011). Majunya perkembangan dunia tersebut, diharapkan lahir generasi bangsa yang cerdas dan terampil serta berkependidikan untuk membangun kemajuan bangsa .

Salah satu institusi yang menyiapkan lulusannya untuk langsung terjun ke dunia kerja adalah Sekolah Menengah Kejuruan (SMK). SMK merupakan suatu lembaga pendidikan yang menghasilkan SDM yang diharapkan memenuhi kebutuhan dunia kerja atau industri. Selaras dengan Peraturan Pemerintah No 29 Tahun 1990 Pasal 1 ayat (3) tentang pendidikan menengah kejuruan yaitu: Pendidikan Kejuruan adalah pendidikan pada jenjang menengah yang mengutamakan pengembangan kemampuan siswa untuk melaksanakan jenis pekerjaan tertentu. Menurut undang-undang Nomor 20 Tahun 2003,

\footnotetext{
1 Mahasiswa Departemen Pendidikan Teknik Mesin FPTK, UPI

2 Dosen Departemen Pendidikan Teknik Mesin FPTK, UPI

3 Dosen Departemen Pendidikan Teknik Mesin FPTK, UPI
} 
tujuan pendidikan menengah kejuruan, yaitu: 1) Menyiapkan peserta didik agar menjadi manusia produktif, mampu bekerja mandiri, mengisi lowongan pekerjaan yang ada sebagai tenaga kerja tingkat menengah sesuai dengan kompetensi dalam program keahlian yang dipilihnya, 2) Menyiapkan peserta didik agar mampu memilih karir, ulet dan gigih dalam berkompetensi beradaptasi di lingkungan kerja dan mengembangkan sikap profesional dalam bidang keahlian yang diminatinya, 3) Membekali peserta didik dengan ilmu pengetahuan teknologi dan seni agar mampu mengembangkan diri di kemudian hari baik secara mandiri maupun melalui jenjang pendidikan yang lebih tinggi, dan 4) Membekali peserta didik dengan kompetensi yang sesuai dengan program keahlian yang dipilih. Sekolah menengah kejuruan untuk menciptakan tenaga kerja yang berkompetensi di bidang keahliannya masing masing. SMK dikatakan berhasil apabila lulusan sekolah tersebut diserap oleh dunia pekerjaan sesuai dengan bidang keahliannya masing-masing.

Berdasarkan data dari Badan Pusat Statistik pada Februari tahun 2016 yang menyatakan jumlah pengangguran sampai Februari mencapai 6,6 juta orang dan 9,84 persen di antaranya merupakan lulusan SMK. Kepala BNSP dan Direktorat Pembinaan SMK juga mengatakan bahwa banyaknya lulusan SMK yang tidak bekerja disebabkan kurang sesuainya kompetensi peserta didik SMK dengan kompetensi tenaga kerja yang dibutuhkan industri. Dilihat dari data BPS dan berita tersebut kurang adanya sinergi antara kompetensi SMK dengan standarisasi kompetensi sesuai kebutuhan kerja (Arifin, 2011).

Hasil wawancara dengan instruktur Drafting Mesin dan CAM BPPLK Bandung yang rutin setiap tahun untuk melakukan TNA (Training Need Analysis) yaitu kegiatan observasi ke setiap perusahaan di Indonesia tentang kompetensi yang dibutuhkan para perusahaan dan permasalahan kompetensi SDM yang ditempatkan di perusahaan. Pada dasarnya kompetensi yang digunakan pada setiap perusahaan sesuai dengan SKKNI (Standar Kompetensi Kerja Nasional Indonesia) yang dibuat oleh Kementrian Tenaga Kerja dan Transmigrasi Republik Indonesia.

SKKNI adalah rumusan kemampuan kerja yang mencakup aspek pengetahuan, keterampilan atau keahlian serta sikap kerja yang relevan dengan pelaksanaan tugas dan syarat jabatan yang ditetapkan sesuai dengan ketentuan peraturan yaitu KEP. 240/MEN/X /2004 keputusan Menteri Tenaga Kerja dan Transmigrasi Republik Indonesia. SKKNI memiliki banyak sektor, salah satunya di sektor logam dan mesin (Susilana, 2011). SKKNI sektor logam dan mesin terdapat beberapa bidang salah satunya adalah bidang menggambar, merencana dan mendesain (drawing, drafing and designing). SKKNI bidang mengambar, merencana dan mendesain ada 11 judul Unit SKKNI diantaranya sebagi 
berikut: ) menggambar dan menginterpretasikan sketsa, 2) membaca gambar teknik, 3) mempersiapkan gambar teknik (dasar), 4) merancang gambar detail pada gambar elektrik/elektronik, 5) merancang gambar tehnik secara rinci (dasar), 6) merancang gambar teknik secara rinci (lanjut), 7) menggambar bagian mesin secara rinci (lanjut), 8) merancang struktur bagian secara rinci (lanjut), 9) menggambar 2D dengan sistem $C A D$, 10) membuat model 3D dengan sistem $C A D$ (11) menerapkan konsep dasar rancangan teknik. Dari 11 judul unit tersebut dijelaskan dalam deskripsi unit apa yang harus dipelajari dan diuraikan dalam kriteria unjuk kerja. Kompetensi bidang menggambar, merencana dan mendesain adalah suatu kompetensi yang penting dalam dunia kerja sebagai pemberi informasi dalam instruksi pekerjaan yang menekankan aspek teknologi, ergonomi, fungsi, bahan, rekayasa, dan proses kerja (Arikunto, 2008). Pentingya kompetensi drawing, designing dan drafting ini penulis tertarik untuk meneliti keterkaitan SKKNI tersebut dengan mata pelajaran di SMK yang mempelajari drawing, designing dan drafting tersebut.

Di Sekolah Menengah Kejuruan, menurut Struktur Kurikulum 2013, mata pelajaran yang mempelajari kompetensi menggambar, merencana dan mendesain adalah Mata Pelajaran Kelompok C3 Paket Keahlian yaitu Mata Pelajaran Produktif Paket Keahlian Teknik Gambar Mesin dari Program Keahlian Teknik Mesin, yang didalamnya terdiri dari tujuh mata pelajaran diantaranya: 1) teknik gambar produksi dan kontruksi mesin 1, 2) desain gambar CAM, 3) teknik gamber mesin 2Dd dengan $C A D$, 4) teknik produksi dan mesin perkakas, 5) teknik gamber mesin 3D dengan CAD 1,6) teknik gambar produksi dan kontruksi mesin 2,7) teknik gamber mesin 3D dengan CAD 1. Mata Pelajaran Prorduktif Paket Keahlian Teknik Gambar Mesin ini diajarkan pada kelas XI dan XII SMK. Pada Kelas X mempelajari Mata Pelajaran Kelompok C1 yaitu Dasar Bidang Keahlian yang didalamnya terdapat mata pelajaran Fisika, Kimia dan Gambar Teknik. Di kelas X juga mempelajari Mata Pelajaran Kelompok C2 yaitu dasar program keahlian diantaranya teknologi mekanik, kelistrikan dan konversi energi, dan mekanika teknik. Materi yang diajarkan dari setiap mata pelajaran berdasarkan Kompetensi Inti lalu turun menjadi Kompetensi Dasar setelah itu keluarlah materi-materi yang harus diajarkan pada setiap mata pelajaran berdasarkan Kompetensi Dasar (Ruhimat, 2009).

Hasil wawancara kepada empat orang lulusan Paket Keahlian Teknik Gambar Mesin Tahun 2016 SMK Negeri 2 Kota Bandung diantaranya, satu lulusan kerja di bidang drafter di perusahaan milik kerabatnya, satu orang bekerja sebagai adminstrasi disekolah swasta, satu orang mengikuti pelatihan $\mathrm{CNC}$ dan satu orang lagi masih belum bekerja 
(Sudarmanto, 2014). Setelah itu penulis melakukan observasi data melihat lulusan Paket Keahlian Teknik Gambar Mesin dari angkatan 2012 sampai 2014 dengan datanya sebagai berikut:

Tabel 1. Jumlah lulusan paket keahlian teknik gambar mesin

\begin{tabular}{llcccc}
\hline \multirow{2}{*}{ No } & \multirow{2}{*}{ Profesi } & \multicolumn{3}{c}{ Tahun Lulusan } \\
\cline { 3 - 6 } & & 2012 & 2013 & 2014 & 2016 \\
\hline 1 & Bekerja & 13 & 16 & 15 & 21 \\
2 & Lanjut Pendidikan & 8 & 6 & 9 & 9 \\
3 & Tidak bekerja atau tanpa keterangan & 17 & 14 & 13 & 3 \\
\hline \multicolumn{3}{r}{ (Sumber: Hub. Industri SMKN 2 Bandung, 2016) }
\end{tabular}

Data pada Tabel 1, menunjukkan mulai tahun 2012 kecederungan jumlah yang bekerja terus naik, yang melanjutkan cenderung stabil dan yang tidak bekerja atau tanpa keterangan cenderung menurun. Lebih dari 30\% lulusan Paket Keahlian Teknik Gambar Mesin SMK Negeri 2 Bandung belum terserap bekerja di Industri. Berdasarkan hasil observasi data nilai dari mata pelajaran produktif Paket Keahlian Teknik Gambar Mesin sudah diatas KKM yaitu di atas 7.4. Oleh karena itu, materi yang terdapat dari Mata Pelajara Paket Kaahlian Teknik Gambar Mesin perlu dianalisis. Lulusan Paket Keahlian Teknik Gambar Mesin masih belum terserap dalam dunia industri sesuai dengan bidang kompetensinya. Sehingga diperlukannya penelitian mengenai keterkaitan Mata Pelajaran Produktif Paket Keahlian Teknik Gambar Mesin dengan SKKNI bidang drawing, drafting and designing. Keterkaitan inilah yang dinamakan dengan prinsip relevansi, yang terdiri atas dua jenis, yaitu relevansi eksternal dan relevansi internal. Relevansi eksternal menunjukkan relevansi antara kurikulum dengan lingkungan hidup peserta didik dan masyarakat dan perkembangan kehidupan masa sekarang dan masa yang akan datang. Relevansi internal menunjukkan relevansi di antara komponen kurikulum itu sendiri (Widiaty, 2013).

\section{METODOLOGI PENELITIAN}

Penelitian ini menggunakan metode deskriptif analitik. Partisipan dalam penelitian ini adalah guru pengampu mata pelajran Paket Keahlian Teknik Gambar Mesin. Materi dan kesesuaian atau relevansi materi Mata Pelajaran Paket Keahlian Teknik Gambar Mesin di SMK Negeri 2 Bandung dengan SKKNI. Pada penelitian ini digunakan beberapa instrumen, yaitu: dokumentasi dan wawancara. Dokumentasi adalah instrumen berupa literatur yang dianggap relevan dengan pokok permasalahan yang diangkat, sehingga dapat 
dijadikan sebagai referensi untuk penelitian. Adapun dokumen yang digunakan dalam penelitian ini adalah dokumen Silabus Mata Pelajaran Paket Keahlian Teknik Gambar Mesin, KI dan KD Mata Pelajaran Paket Keahlian Teknik Gambar Mesin, dan file SKKNI sektor logam dan mesin. Ketiga dokumen tersebut digunakan untuk menghimpun data awal berupa Kompetensi dasar Mata Pelajaran Paket Keahlian Teknik Gambar Mesin dan Deskripsi Unit SKKNI Drawing, Designing and Drafting lalu dikonfirmasikan kesesuaiannya kepada Guru Mata Pelajaran pengampu. Lembar wawancara yang digunakan meliputi lembar wawancara dengan guru pengampu Mata Pelajan Paket Keahlian Teknik Gambar Mesin, Narasumber dari BPPLK Bandung dengan wawancara semi terstruktur dan alumni lulusan siswa jurusan Teknik Gambar Mesin SMK Negeri 2 Bandung.

\section{HASIL PENELITIAN}

Hasil penelitian dirangkum pada Tabel 1, sebagai berikut:

Tabel 1. Persentase Relevansi Mata Pelajaran Keahlian Teknik Gambar Mesin dengan SKKNI

\begin{tabular}{clc}
\hline No & Mata Pelajaran Keahlian Teknik Gambar Mesin & Relevansi (\%) \\
\hline 1 & Teknik Gambar Produksi dan Konstruksi Mesin I & 83,6 \\
2 & Teknik Gambar Mesin 2D dengan CAD & 74 \\
3 & Teknik Produksi dan Mesin Perkakas & 64,5 \\
4 & Teknik Gambar Mesin 3D dengan CAD & 75,5 \\
5 & Teknik Gambar Produksi dan Kosntruksi Mesin II & 85 \\
6 & Teknik Gambar Mesin 3D dengan CAD II & 84 \\
7 & Teknik Desain Gambar dengan CAM $\quad$ Rata-rata & 94 \\
& & 80,09 \\
\hline
\end{tabular}

Rata-rata persentase Relevansi (Tabel 1) Mata Pelajaran Produktif Paket Keahlian Teknik Gambar Mesin dengan SKKNI adalah 80,1\%. Angka ini dihasilkan dari perhitungan rata-rata persentase dari tiap mata pelajaran produktif Paket Keahlian Teknik Gambar Mesin. Persentase tersebut Kategori relevansi dari Mata Pelajaran Produktif Paket Keahlian Teknik Gambar Mesin dengan SKKNI adalah relevan. Mata pelajaran Teknik Desain Gambar dengan $C A M$ tingkat relevansinya dengan SKKNI paling tinggi lalu yang kedua Teknik Gambar Produksi dan Kontruksi II dan untuk yang paling akhir adalah Teknik Produksi dan Mesin Perkakas dengan tingkat relevansi relevan. Berdasarkan hasil relevansi tiap mata pelajaran dapat di rata-ratakan tingkat relevansi dari tiap mata pelajaran (Mulyasa, 2006). 
Diketahui bahwa materi Mata Pelajaran Produktif Paket Keahlian Teknik Gambar Mesin sudah relevan atau belum dengan SKKNI. Deskripsi Materi Mata Pelajaran Teknik Gambar Produksi dan Kontruksi Mesin I sangat relevan dengan SKKNI bidang drawing, designing dan drafting. Persentase deskripsi materi yang relevan sebesar 83,6\% dan 16,4\% yang tidak relevan dengan uraian deskripsi unit SKKNI yaitu diantaranya judul unit merancang gambar detail pada gambar elektrik dan elektronik; menggambar 2D dengan sistem $C A D$; dan membuat Model 3D dengan sistem $C A D$.

Deskripsi Materi Mata Pelajaran Teknik Gambar Mesin 2D dengan CAD relevan dengan SKKNI bidang drawing, designing dan drafting. Persentase deskripsi materi yang relevan sebesar $74 \%$ dan $26 \%$ yang tidak relevan dengan uraian deskripsi unit SKKNI yaitu diantaranya: merancang gambar detail gambar elektronik; perhitungan teknik dalam maerancang gambar tekni secara rinci; membuat model 3D dengan sistem $C A D$ dan penentuan harga dalam konsep dasar rancangan teknik.

Deskripsi Materi Mata Pelajaran Teknik Produksi Mesin dan Perkakas relevan dengan SKKNI bidang drawing, designing dan drafting. Persentase deskripsi materi yang relevan sebesar $64,5 \%$ dan 35,5\% yang tidak relevan dengan uraian deskripsi unit SKKNI yaitu diantaranya identifikasi bagian-bagian gambar; menerbitkan gambar; dokumentasi gambar sesuai prosedur; merancang gambar detail pada gambar elektronik; penentuan persyaratan part atau bahan sesuai katalog; merancang gambar struktur; menggambar 2D dengan sistem $C A D$; dan membuat model dengan sistem $C A D$.

Deskripsi Materi Mata Pelajaran Teknik Gambar Mesin 3D dengan CAD I relevan dengan SKKNI bidang drawing, designing dan drafting. Persentase deskripsi materi yang relevan sebesar $75,5 \%$ dan $24,5 \%$ yang tidak relevan dengan uraian deskripsi unit SKKNI yaitu diantaranya: merancang gambar detal pada gambar elektronik dan penentuan harga dalam konsep dasar rancangan teknik.

Deskripsi Materi Mata Pelajaran Teknik Gambar Produksi dan Kontruksi Mesin II sangat relevan dengan SKKNI bidang drawing, designing dan drafting. Persentase deskripsi materi yang relevan sebesar $85 \%$ dan $15 \%$ yang tidak relevan dengan uraian deskripsi unit SKKNI yaitu diantaranya: merancang gambar detail pada gambar elektronik; menggambar 2D dengan sistem CAD; dan membuat model 3D dengan sistem CAD.

Deskripsi Materi Mata Pelajaran Teknik Gambar Mesin 3D dengan CAD II sangat relevan dengan SKKNI bidang drawing, designing dan drafting. Persentase deskripsi materi yang relevan sebesar $84 \%$ dan $16 \%$ yang tidak relevan dengan uraian deskripsi unit 
SKKNI yaitu merancang gambar detail pada gambar elektronik;penentuan harga dalam dasar perancangan teknik.

Deskripsi Materi Mata Pelajaran Teknik Desain Gambar dengan CAM sangat relevan dengan SKKNI bidang drawing, designing dan drafting. Persentase deskripsi materi yang relevan sebesar $94 \%$ dan 6\% yang tidak relevan dengan uraian deskripsi unit SKKNI yaitu diantaranya merancang gambar detail pada gambar elektronik, penentuan harga dalam dasar perancangan teknik.

Data ini dapat disosialisasikan kerelevanan materi kepada guru pengampu di Sekolah khususnya Guru Pengampu Mata Pelajara Produktif Paket Keahlian Teknik Gambar Mesin. Tujuan yang ingin dicapai sekolah dapat terwujud dan untuk merealisasikan bagian materi yang belum relevan, bisa dintregasikan pada mata pelajaran yang berhungan dengan materi atau dimasukan pada muatan lokal. Hal ini memungkinkan guru pengampu memperoleh gambaran relevansi mata pelajaran yang diampunya dengan SKKNI (Meredith and Burkle, 2008), sehingga memudahkan dalam mengilustrasikan pengaplikasian materi yang diajarkannya kepada siswa.

\section{KESIMPULAN}

Kesimpulan penelitian ini, sebagai berikut: materi mata pelajaran dalam Mata Pelajaran Teknik Gambar Mesin secara keseluruhan memiliki tingkat kesesuaian dengan SKKNI sebesar 80,1\% dan masuk dalam kategori relevan. Mata Pelajaran Teknik Gambar Mesin dihasilkan suatu pemetaan sekuen yang relevan antara deskripsi materi Mata Pelajaran Teknik Gambar Mesin dengan deskripsi unit SKKNI bidang drawing, designing dan drafting.

\section{REFERENSI}

Arifin, Z. (2011). Konsep dan Model Pengembangan Kurikulum. Bandung: PT Remaja Rosdakarya.

Arikunto, S. (2008). Dasar-dasar Evaluasi Pendidikan. Jakarta: PT. Rineka Cipta.

Idi, A. (2011). Pengembangan Kurikulum: Teori dan Praktik. Jogjakarta: Ar-Ruzz Media.

Widiaty, I. (2013). Relevansi kurikulum SMK berbasis industri kreatif dengan metode extrapolation and the econometric approach. Invotec, IX (1). hal. 29-42. 
Meredith, S. and Burkle, M. (2008). Building bridges between university and industry: Theory and practice. Journal Education and Training 50 (3) hal. 199-215.

Mulyasa, E. (2006). Kurikulum Berbasis Kompetensi. Bandung: Remaja Rosda Karya.

Ruhimat, Dkk. (2009). Kurikulum dan pembelajaran. Bandung: Universitas Pendidikan Indonesia.

Sudarmanto. (2014). Kinerja dan Pengembangan Kompetensi SDM, Yogyakarta: Pustaka Pelajar.

Susilana, R. (2011). Kurikulum dan Pembelajaran. Bandung: Jurusan Kurtekpen FIP UPI. 